\title{
FILIADOS E MILITANTES PARTIDÁRIOS: PERFIS DA FILIAÇÃO PARTIDÁRIA NUMA PERSPETIVA COMPARADA
}

\author{
Paula Espírito Santo \& Bruno Ferreira Costa
}

\begin{abstract}
Resumo
O ponto de partida deste estudo reside na constatação de que o declínio da mobilização partidária e socialização política é de grande importância para entender melhor a democracia e como ela pode sobreviver. A nível nacional, a atividade dos membros dos partidos tem características significativas, que estão profundamente assentes na cultura política do país. A nível individual, o ativismo partidário é uma missão específica para cada pessoa. A filiação partidária não é apenas parte de sua história de vida única, mas também serve como um elo de ligação na cadeia de sustentabilidade do partido. O estudo da mobilização partidária e a socialização política carecem de maior desenvolvimento no contexto português, particularmente o estudo da escolha da atividade dos membros do partido. O principal objetivo deste artigo é o de identificar, numa perspetiva comparada, os traços sociodemográficos básicos assim como um conjunto de atitudes político-ideológicas essenciais distintivos de membros partidários de três partidos Portugueses principais com assento parlamentar (Partido Socialista - PS, Partido Social Democrata Militantes; partidos; filiados partidários; democracia; socialização PSD e Centro Democrático e Social/Partido Popular - CDS/PP). A metodologia deste estudo baseia-se na técnica da sondagem, validada na pesquisa do projeto MAPP (Working group on Members and Activists of Political Parties). Este é um objeto escassamente analisado em Portugal (Stock et al. 1985; Lisi \& Espírito Santo, 2017), sendo que os resultados esperados serão os de contribuir para identificar causalidades no que se refere à diminuição e à falta de interesse pela participação partidária, mas também política em geral, por um lado. Por outro, pretende-se contribuir para conhecer melhor, por dentro dos partidos, quem são os filiados partidários e como poderão distinguir-se dos militantes.
\end{abstract}

\section{Patavras-chave}

Militantes; partidos; filiados partidários; democracia; socialização

\begin{abstract}
Our starting point is that the decline of party mobilisation and political socialisation is of great importance to better understand both how democracy works and how it may survive. At national level, party member activity has significant features that are deeply seated in the nation's political culture. At an individual level, party activism is a mission particular to each person. It is not only part of his or her unique life story but serves also as a link in the chain of party sustainability. Party mobilisation and political socialisation warrant further development in the Portuguese context, particularly the study of the choice of party members' activity upstream. The main objective of this article is to identify, in a comparative perspective, sociodemographic basic traits, and a set of essential political and ideological attitudes of party members of three main Portuguese parties with parliamentary representation (Socialist Party - PS, Social Democratic Party - PSD, and Centro Democrático Social / Partido Popular - CDS/PP). The methodology of this study is based on the survey technique validated in the MAPP project (Working group on Members and Activists of Political Parties). This is an object scarcely analyzed in Portugal (Stock et al., 1985; Lisi \& Espírito Santo, 2017), and its expected results will be those of contributing to identify causalities regarding the decrease and lack of interest for parties' activities in politics in general, on the one hand. On the other hand, it is intended to contribute to getting to know
\end{abstract}


better, in an inside party perspective, who are the party affiliates and how they can distinguish themselves from the activists.

\section{KEYWORDS}

Activists; parties; party members; democracy; socialization

\section{INTRODUÇÃo}

Os partidos políticos e os seus filiados são duas faces inseparáveis de mobilização não só política como da própria democracia. Em Portugal, a democracia seria um marco fundamental para o recrusdecimento da actividade partidária militante. No plano partidário, o pós 25 de abril de 1974, decorrente da revolução dos cravos, foi caracterizado não só pela proliferação de partidos políticos', mas igualmente pela arregimentação de grandes franjas de apoio junto do eleitorado, constituindo a militância partidária uma forma direta de participação política. O advento da democracia veio acompanhado, no pós-revolução, por uma forte vontade inicial de participação dos cidadãos nos destinos da sociedade e dos partidos, mas que, gradualmente viria a revelar-se um indicador com tendência a perder importância à medida que a desilusão com os partidos e a esperança na democracia se instalava. Ou seja, verifica-se, cada vez mais, que a realidade da filiação partidária se encontra numa fase descendente do seu ciclo, a qual acompanha o desinteresse e desilusão com a política, a democracia e a falta de confiança nas instituições democráticas. $O$ entendimento das motivações dos filiados partidários poderá constituir um barómetro importante quanto ao estado da democracia, em especial no caso de uma jovem democracia como a Portuguesa.

A montante da filiação partidária encontra-se o processo de socialização política, A socialização política é entendida como "a forma através da qual os valores políticos são formados e a cultura política é transmitida de uma geração para a outra" (Almond, Powell, Strom \& Dalton, 2000, p. 56). A socialização política refere-se ao conjunto de experiências que contribuem particularmente para a formação da auto-imagem do indivíduo em relação ao próprio sistema político e em relação às instituições da sociedade (Oppo, 1986), sendo que, nas suas origens, reforça-se a importância do modo como as crianças e os adolescentes assimilam as suas atitudes políticas (Berger \& Luckamann, 1961). O processo de socialização política subentende o envolvimento e participação natural de cada cidadão no Estado, desde o seu nascimento até à morte, e deriva do papel dos diversos agentes de socialização política, de onde se destacam a família, a escola, os grupos de pares e vizinhança, a comunicação social, as elites políticas, a propaganda e as redes sociais à distância. Os agentes de socialização política abrem ao cidadão um caminho particular que o "capacita de instrumentos de envolvimento e actuação sociopolítica que the permitem desenvolver e desempenhar a sua capacidade de cidadania" (Espírito Santo, 2006, p. 122).

\footnotetext{
' Nas eleições para a Assembleia Constituinte de 1975 apresentam-se a votos 14 partidos. Retirado de: www.cne.pt.
} 
O posicionamento dos meios de comunicação social como fonte de informação e formação da opinião pública constitui um dos elementos clássicos identificados como suporte fundamental de construção e consolidação das representações sociais e políticas (Lasswell, 1931; Berelson \& Grazia, 1947; Harrop \& Miller, 1987; Popper \& Condry, 1993; Norris, 2002). O papel dos orgãos de comunicação social, nas democracias ocidentais, viria a ser fundamental, sobretudo, a partir da segunda metade do século XX, como complemento ao papel tradicional dos primários agentes de socialização política, como a família e a escola ou os grupos de pares e vizinhança.

A partir, essencialmente, do século XXI, as redes sociais viriam a sobressair como um poderoso mecanismo e agente de socialização política, funcionando como indutor, catalizador ou reforço do posicionamento sociopolítico individual e coletivo, em face da realidade e atualidade político-partidária. As redes sociais são, na atualidade, um elemento central na caminhada para a construção da opinião pública democrática e um agente de socialização política vital e permamente na democracia.

De que modo os diversos agentes de socialização política, e em especial a família, promovem a participação partidária é a questão clássica e inicial, de fundo, neste estudo. Adicionalmente procura-se identificar a relação entre o percurso educativo, profissional e social com a participação partidária. Estas são algumas das questões que, intrinsecamente estarão na base do estudo efetuado, o qual procura fazer sobressair a importância dos mecanismos de socialização política na mobilização dos filiados partidários.

O objetivo central deste estudo visa identifificar moldes sociodemográficos e atitudionais-chave que definem a atividade dos filiados partidários, e podem permitir explicar a sua capacidade para a mobilização partidária e política. No plano metodológico, este estudo, baseado na aplicação de sondagem, procura aprofundar o conhecimento sobre as bases sociodemográficas e atitudinais que conduzem a uma participação política ativa no seio dos partidos. A questão da pesquisa é: "quão próximos estão os membros partidários em relação ao partido?" e procura centrar-se nas posições ideológicas e na participação real nas atividades do partido. Os resultados esperados perspetivam o aprofundamento ao nível do conhecimento da realidade intra-partidária militante, bem como - levantamento de pistas sobre os mecanismos a adotar pelos partidos, de forma a inverter a tendência de diminuição de filiados nas últimas décadas no panorama europeu.

Incidimos a análise sobre os filiados do PS, PSD e CDS/PP, sendo a opção justificada por serem estes partidos com assento parlamentar, e também pela sua disponibilidade em colaborar na presente investigação. A nível metodológico foi aplicado um inquérito online ao universo de filiados do do PS e CDS/PP assim como aos delegados do PSD, entre finais de dezembro de 2012 e finais de setembro de 2014 . O objetivo geral das sondagens aplicadas foi analisar as características sócio-demográficas dos filiados partidários, as suas motivações políticas e a sua visão face à linha ideológica do partido.

A capacidade de um partido de recrutar e mobilizar está diretamente relacionada com a sua estrutura e vocação. Do ponto de vista histórico, os grandes partidos de massa basearam a sua ação numa perspetiva eminentemente societária. Peter Mair (2003, p. 16) afirmou que "as partes não diminuíram de facto como tal, mas mudaram 
e encontram-se cada vez mais embutidas nas instituições". Há um esforço menos visível das partes na busca de propaganda ou mobilização de partidários e apoiantes, com maior foco nos meios de comunicação social, nos especialistas em marketing político e nas novas plataformas online para atrair novos membros do partido.

$\mathrm{Na}$ distinção clássica entre os partidos de massas e os partidos de quadros, Duverger (1951) estabeleceu como elementos centrais dessa diferenciação as modalidades de adesão ou filiação partidária, os graus de participação partidária e a natureza da participação partidária. Otto Kirchhmeimer (1966) demarcou de modo pioneiro a expressão dos partidos catch all e identificou que estes resultam de um sistemático processo de despolitização e desideologização dos seus programas, indo ao encontro de temas mais consensuais da política e sociedade (que na primeira metade do século XX refletiam o bem estar económico vivido no pós II Guerra Mundial) e com objetivos imediatos de captura do poder político, pelo êxito eleitoral. Já sobre os designados "partidos de eleitores", Jean Charlot (1970, p. 63) considerava que estes exprimem "um fundo comum de valores, bastante amplo para reunir ao seu redor o máximo de apoiantes". Os estudos sobre os perfis dos filiados tendem a convergir sobre as divisões entre grandes tipologias de partidos (van Haute, 2011; van Haute \& Gauja, 2015). Apesar da tendência geral para o declínio do número de membros dos partidos, e da sedimentação da designada política auto-referencial ligada à organização dos partidos de cartel (Katz \& Mair, 2009; Poguntke, Scarrow \& Webb, 2016) defendemos que as características tradicionais de partido catch all estão na origem do crescimento e ambição política dos partidos em estudo, PS, PSD e CDS/PP, e permitem chegar à sua configuração político-ideológica.

PS e PSD são dois partidos de massas que têm liderado o Parlamento e o Governo, desde 1975 (PS), 1976 (PS) e 1980 (AD - Aliança Democrática, entre PSD, CDS e PPM Partido Popular Monárquico). O CDS/PP é um partido baseado na valorização de uma ideologia ancorada, originalmente, na sua fundação, na democracia cristã. No entanto, verificou-se, gradualmente, por parte do CDS/PP o recurso e utilização de temas/áreas específicos (exemplo: a segurança e a agricultura) como mote central da sua mensagem e estratégia política. Também se verificou uma abertura do espectro ideológico-político de centro direita, no sentido de canalizar não apenas algumas franjas de um eleitorado de direita mais ortodoxo como da direita ideologicamente moderada. O CDS/PP tem reforçado a sua base de valores-chave, a qual é visível no plano da sua ação política concreta, tanto a nível parlamentar, como a nível governamental, como membro da coligação com o Partido Social Democrata (PSD) nas eleições legislativas de 2011 e $2015^{2}$.

\section{O MILITANTISMO PARTIDÁRIO}

A capacidade de recrutamento e mobilização partidária está diretamente relacionada com a própria estrutura e vocação do partido. Recorrendo a uma perspetiva histórica

2 Nas eleições de 2015, a coligação durou apenas 2 semanas, devido à não aprovação do programa de governo pela maioria de Esquerda na Assembleia da Republica. Em 2015, a coligação ('Portugal à Frente' - PàF) tinha minoria no Parlamento. Como consequência, o Partido Socialista aliou-se ao Partido Comunista Português, ao Partido Ecologista "Os Verdes" e ao Bloco de Esquerda para aprovar um governo liderado por António Costa. 
verifica-se que os grandes partidos de massas baseavam a sua ação numa perspetiva, iminentemente, societária. Peter Mair (2003, p. 285) defende que os "partidos enquanto tais não declinaram, mas modificaram-se e encontram-se hoje cada vez mais implantados nas instituições". Observamos um esforço menos visível dos partidos nas tarefas propangandísticas e mobilizadoras dos militantes/simpatizantes, em detrimento de um maior relevo dos meios de comunicação social, dos profissionais do marketing político e das novas plataformas electrónicas como agentes angariadores de novos filiados partidários.

A importância dos partidos políticos é inegável, sendo que "o desenvolvimento dos partidos aparece ligado ao da democracia, quer dizer à extensão do sufrágio popular e das prerrogativas parlamentares" (Duverger, 1951, p. 24). No entanto, apesar da importância democrática dos partidos identifica-se, simultaneamente, um declínio sociológico da capacidade dos partidos enquanto organizações de membros e enquanto veículos de participação política, o que pode ser explicado por diversos processos de atualização das bases de dados de filiados por parte dos partidos políticos (Katz \& Mair, 1992), mas também pelo decréscimo da importância dos partidos políticos no plano da mobilização política (Dogan, 1995; Gray \& Caul, 2000), ligada ao decréscimo da confiança no Governo e nas instituições democráticas, à despolarização partidária e à volatilidade eleitoral (Norris, 1997; Mair \& Keman, 2002; Espírito Santo, 2011).

Outros contributos permitem verificar que as organizações partidárias têm sofrido nas últimas décadas profundas transformações, cujo impacto no aumento da tendência abstencionista é considerável, ao mesmo tempo que se verifica uma diminuição da identificação partidária (Wattenberg \& Dalton, 2000). Este processo de identificação é vital para compreender o fenómeno da participação eleitoral, que enquadramos como uma das formas de participação política, sendo que não é possível existir eleições sem participação. Verifica-se, por isso, uma verdadeira "participação política quando os cidadãos influenciam de forma determinante o processo de decisão política" (Meirinho Martins, 2003, p. 23).

A identificação partidária pode permitir igualmente cimentar a dimensão competitiva dos partidos, sendo que o percurso de identificação e mobilização partidárias constitui-se "um elo entre muitos na cadeia de sustentabilidade humana do partido político, com múltiplos aspetos de partilha e vivência comuns em relação aos seus companheiros de luta partidária" (Espírito Santo, 2011, p. 145). Os "militantes partidários constituem-se como o elemento central da dinamização do partido político pelo papel vital que desempenham enquanto mobilizadores da ação política" (Espírito Santo, 2011, p. 146). O estudo dos padrões de comunicação interna dos partidos (comparação entre PSD, PS e CDS/PP), desenvolvido por Figueiras e Fonseca (2017) identificou uma relação entre os níveis internos de institucionalização partidária e os patamares de integração e centralização organizacionais, os quais poderão diretamente influenciar os moldes de intervenção dos filiados partidários. Neste plano, os níveis de inclusividade podem constituir um resultado diretamente afeto ao tipo de estratégia comunicacional que o partido define, no plano dos seus públicos internos, e dos seus filiados em particular. 


\section{Filiação Partidária EM Portugal}

A afirmação dos partidos políticos no pós 25 de abril de 1974 foi acompanhada por um crescimento efetivo do número de filiados/militantes. Contudo escasseiam os estudos sobre o fenómeno da socialização política e da ação dos filiados partidários, no seio do seu partido, em Portugal. Tal facto resulta, diretamente, da dificuldade de aceder às bases de dados internas dos partidos, estruturas fechadas que procuram proteger o seu funcionamento interno dos meios de comunicação social. Decorrente dessa notória dificuldade, provavelmente, o interesse pela área do militatismo partidário foi relegado para um plano secundário na investigação sociológica e política.

A contribuição de Stock e colegas (1985), intitulada Os Partidos em Congresso 1981, é, muito provavelmente, a exceção, até à data, neste panorama de escassez de estudo do militantismo em Portugal, ao focar os congressistas dos principais partidos políticos Portugueses, em 1981. Tratou-se de uma abordagem sociológica, baseada em inquérito, ao perfil e às motivações dos delegados partidários em congresso do PS (Partido Socialista), PSD (Partido Social Democrata), CDS (Centro Democrático Social), MDP (Movimento Democrático Popular) - partido, entretanto, extinto e PPM (partido popular monárquico). No espectro dos delegados ao congresso destes partidos salientam-se os resultados seguintes:

em cada um dos quatro partidos estudados, cerca de um terço dos delegados desempenha profissões que se enquadram na categoria que classificámos como classe média. Contudo, enquanto no CDS e no PSD os delegados com profissões enquadráveis na classe média-alta constituem $40 \%$ da amostra de cada um dos partidos, no PS e no MDP este valor é de cerca de 20\%. (Stock et al., 1985, p. 134)

Em termos de posicionamento ideológico, com base numa escala esquerda-direita com dez posições, verifica-se que o auto-posicionamento dos congressistas coloca o MDP "bastante à esquerda", o PS no centro-esquerda, o PSD no centro direita e o CDS "bastante à direita" (Stock et al., 1985, p. 139), num posicionamento similar ao verificado actualmente. Ou seja, "os resultados (...) confirmaram a polarização do novo sistema de partidos portugueses, nos termos tradicionais de esquerda/direita, dado que os delegados de cada um dos partidos analisados assumem atitudes claramente identificáveis ao longo dum espectro político-ideológico, o qual, numa perspetiva comparativa transnacional, surge como particularmente amplo" e ainda que "os delegados dos partidos estudados parecem mesmo (...) ser mais motivados por preocupações de ordem política e ideológica, que objetiva e materialista, especialmente no que se refere aos partidos de esquerda" (Stock et al., 1985, p. 147). Esta contribuição demarcou não apenas a natureza e perfis das elites partidárias, mas, sobretudo, a sua importância estratégica "no lançar dos alicerces para novas orientações futuras" (Stock et al., 1985, p. 28). Estas elites partidárias seriam o germen da cultura partidária portuguesa, num momento pós-revolucionário, onde o cenário político interno exigia estabilidade e consolidação política, social e económica e Portugal aspirava a ser uma nova democracia sustentável. 
Ainda que ligado, indiretamente, ao fenómeno do militantismo, é de referir ainda a contribuição de Braga da Cruz (1985) que analisa a participação política dos jovens, com base num inquérito aplicado a elementos de organizações políticas juvenis, sendo que as mesmas foram criadas pelos respetivos partidos ou à sombra deles, como forma de garantir uma ponte de contato entre os partidos e os jovens. Um dos elementos de análise do referido estudo prende-se com a constatação que alguns partidos congregam em si mais filiados jovens que as próprias juventudes partidárias, ou seja, o papel da juventude partidária ainda é subsidário do partido, não tendo a mesma capacidade de mobilização. Braga da Cruz (1985) descreve as elites políticas juvenis de forma bastante clara, identificando um pendor, maioritariamente, masculino, estudantil, de solteiros e a residir com os pais. O estudo confirma igualmente a importância do processo de socialização, nomeadamente, o contributo da família, dos amigos e dos meios de comunicação social (acesso à informação) como fatores decisivos para um maior envolvimento político. Villaverde Cabral (1995) analisou igualmente os grupos de simpatia partidária em Portugal, tendo recorrido a uma sondagem para projetar a percentagem de filiados em Portugal, valor que, em 1991, correspondia, segundo este estudo, a 415.000 pessoas. O autor destaca o facto da maioria dos filiados pertencer a estratos mais instruídos da população, sendo que "quanto mais favorável é a avaliação da equidade do sistema de oportunidades e recompensas sócio-económicas, mais forte se revela a tendência para participar de forma associada na vida cívica e para assumir o exercício da cidadania política" (Cabral, 1995, p. 200).

Considerando o cenário atual, a definição formal do membro do partido, dentro dos critérios e condições para a adesão, é expressa nos estatutos de cada partido, e é bastante semelhante e suficientemente extensa, entre todos os partidos, como pode ser visto na tabela abaixo.

\begin{tabular}{ll}
\hline \multicolumn{1}{c}{ PARTIDO } & \multicolumn{1}{c}{ CRITERIOS E CONDIÇÕES } \\
\hline $\begin{array}{l}\text { PSD (Partido Social } \\
\text { Democrata): }\end{array}$ & $\begin{array}{l}\text { Os cidadãos portugueses podem tornar-se membros do partido gozando dos seus direitos } \\
\text { políticos completos aderindo ao programa e à Constituição do partido. } \\
\text { Os cidadãos estrangeiros têm igualmente o direito de se tornar membros do partido. }\end{array}$ \\
\hline PS (Partido Socialista) & $\begin{array}{l}\text { Um membro do Partido Socialista é alguém que, depois de concordar com a declaração de } \\
\text { princípios, os estatutos do programa e as regras do partido, se inscreve como um membro } \\
\text { ativo e é aceite pelos órgãos competentes. }\end{array}$ \\
\hline $\begin{array}{l}\text { CDS/PP (Centro Democrático } \\
\text { Social/Partido Popular) }\end{array}$ & $\begin{array}{l}\text { Os cidadãos portugueses com mais de 18 anos podem ser filiados no Partido CDS e gozar } \\
\text { vados pelo Conselho Nacional. } \\
\text { Os cidadãos estrangeiros que residem legalmente em Portugal e têm direitos políticos tam- } \\
\text { bém podem estar afiliados ao CDS - Partido Popular. }\end{array}$ \\
\hline PCP (Partido Comunista & $\begin{array}{l}\text { Qualquer pessoa pode tornar-se membro do partido comunista, desde que respeite o pro- } \\
\text { grama e os estatutos do partido, realize os deveres ativos fundamentais nas organizações } \\
\text { do partido e pague as contribuições necessárias. }\end{array}$ \\
\hline Bortuguês) & $\begin{array}{l}\text { Os aderentes do "bloco de esquerda" são aqueles que consideram manifestar o desejo de } \\
\text { se juntar ao movimento e ter pleno gozo de seus direitos políticos. }\end{array}$ \\
\hline
\end{tabular}


Após a afiliação formal ao partido, cada membro compromete-se a pagar uma taxa mensal, geralmente de natureza simbólica, sendo um mínimo de um euro por mês, 12 euros por ano. Isto em relação aos partidos representados no Parlamento, que beneficiam de uma associação mais significativa. No entanto, esta taxa não é obrigatória e pode ser ajustada de acordo com a capacidade do membro de pagar, como é o caso dos membros do Partido Comunista Português.

Os estatutos de cada partido incluem direitos e obrigações detalhados para os respetivos membros. Todos os partidos têm alguns princípios em comum. Normalmente, os primeiros princípios dos "direitos dos membros do partido" sublinham a obrigação de participar das atividades dos partidos e o direito de eleger e ser eleito. Estes dois direitos e princípios são expressos nos estatutos do PSD, PS, CDS e BE, por exemplo. No que diz respeito ao Partido Comunista, há um foco na "defesa da unidade e da coesão do partido", bem como nas "opiniões e decisões coletivas" e na "responsabilidade coletiva".

Considerando as obrigações dos membros do partido, os princípios mais comuns são participar ativamente nas atividades do partido e manter confidencialmente as questões internas do partido. Em relação ao Partido Comunista, as obrigações dos membros do partido são bastante detalhadas (13 princípios) e incluem uma forte consciência e um forte compromisso de participação em todas as atividades partidárias, além de contribuir para o desenvolvimento do partido, de modo a defender uma base de "democracia interna".

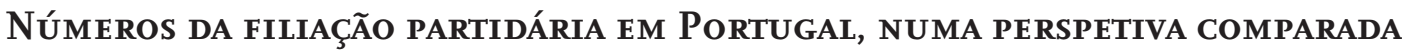

Antes de 1974, Portugal viveu o que se denomina o período do "Estado Novo". A partir de 1933, o único partido formalmente aceite pelo Estado era a "União Nacional'"UN. Os estatutos deste partido foram inspirados em Oliveira Salazar, que era então Ministro das Finanças e, entre 1933 e 1968, foi Presidente do Conselho de Ministros. O nome deste partido único foi adotado com o objetivo de unir toda a população portuguesa em torno da figura de Oliveira Salazar e dos valores da pátria. Marcelo Caetano, mais tarde, sucederia a Salazar, até à revolução de 1974. O nome do partido mudaria em 1970 para "Acção Nacional Popular - ANP", após um processo de reorganização. Os seus estatutos definiriam este partido como uma "associação cívica para promover a participação cidadã no estudo dos problemas da nação portuguesa e soluções práticas para ser mais consistente com os princípios fundamentais professados. Durante o período do Estado Novo, o Partido Comunista Português, fundado em 1921, sofreu um período de existência clandestina, tendo os seus membros sido monitorizados de perto e vivenciado o uso da repressão e força nas mãos da polícia política (PIDE - Polícia Internacional de Defesa do Estado).

Através da Tabela 2 verifica-se que em 2010 existia um total de 337 mil membros partidários em Portugal, o que representava 3,2\% da população residente e $3,4 \%$ do eleitorado nacional. Essa proporção diminuiu em 2012 para cerca de 2,7\% da população 
residente e $3 \%$ da população votante. No entanto, de acordo com os partidos, há um número considerável de membros que não pagaram as quotas. Por exemplo, considerando os dados fornecidos pelo PS, de aproximadamente 83.000 membros, apenas 49.000 pagaram as suas quotas. Os social-democratas consideraram 112 mil membros pagantes, bem como o CDS/PP registou cerca de 30 mil membros pagantes. O BE considerou que apenas cerca de metade eram membros pagantes e o Partido Comunista indicou que cerca de $43 \%$ eram "membros ativos" com quotas pagas. Estes dados reduzem significativamente a proporção real de membros do partido que podem ser considerados como membros ativos, e que participam e estão envolvidos nas atividades dos partidos. Os partidos parecem condenados a lidar, de forma permantente, com um desinteresse progressivo dos seus membros.

Quanto à evolução do número de filiados (Espírito Santo, 2011) verificam-se consideráveis flutuações, desde a data de fundação dos mesmos, fruto de processos de refiliação e "limpeza" dos cadernos de filiados. Os aumentos súbitos do número de filiados decorrem, em regra, de períodos de entusiasmo coletivo, logo após a vitória nas eleições.

\begin{tabular}{|c|c|c|c|c|c|c|c|c|}
\hline Partido & Fundado em & 1976 & 1983 & 1990 & 2001 & 2003 & 2010 & 2012 \\
\hline PSD & 1974 & 7.943 & - & 29.005 & 86.674 & 120.720 & 131.488 & 112.009 \\
\hline PS & 1973 & - & - & 55.358 & 125.313 & 72.710 & 116.000 & 83.500 \\
\hline CDS-PP & 1974 & - & - & - & 32.571 & 35.972 & 22.435 & 29.655 \\
\hline PCP & 1921 & 115.000 & 200.753 & - & 131.000 a) & 131.000 a) & 58.928 & 60.484 \\
\hline BE & 1999 & - & - & - & - & 5.035 & 8.000 & 9.600 \\
\hline $\begin{array}{l}\text { Total de membros } \\
\text { partidários }\end{array}$ & & - & - & - & 375.558 & 365.437 & 336.857 & 295.248 \\
\hline Votantes & & 6.457 .440 & $7.450,108$ & $9,970.441$ & 8.695 .958 & 8.687 .945 & 9.740 .366 & 9.721 .406 \\
\hline $\begin{array}{l}\text { População } \\
\text { residente }\end{array}$ & & 9.403 .810 & $9-969.940$ & $9,970.441$ & 10.394 .669 & 10.473 .050 & 10.572 .157 & 10.562 .178 \\
\hline
\end{tabular}

a) Dados disponíveis apenas em ano de congresso partidário, o qual ocorre a cada quatro anos

Embora se verifique uma redução do número de filiados nas democracias consolidadas da Europa (Wattenberg \& Dalton, 2000; Whiteley, 2009, van Haute \& Gauja, 2015), os líderes partidários têm procurado traçar caminhos de aproximação aos filiados, nomeadamente através da promoção da sua participação na escolha dos seus representantes. No caso português, o PS, o PSD e o CDS/PP garantem o direito de eleição do líder aos seus filiados, através de eleições gerais. Este fenómeno é verificado em diversos 
países, onde existe igualmente uma maior participação dos filiados na definição das políticas a adotar pelo partido (Scarrow, Webb \& Farrel, 2000; Pennings \& Hazan, 2001; Seyd \& Whiteley, 2002). No entanto, a eleição direta do líder não é um caminho isento de barreiras, uma vez que a uma maior participação dos filiados na vida partidária poderá corresponder a uma perda de influência das elites que têm comandado os destinos do partido. Sobre o impacto deste processo na atração dos filiados, em termos de participação efetiva nos destinos do partido, fica a questão acerca da sua eficácia.

Quanto à quantificação do número de filiados nos partidos políticos, no contexto europeu constatam-se diferenças consideráveis quanto à capacidade de os partidos angariarem novos filiados. Neste caso concreto releva o facto de nas últimas décadas o número de filiados nos países de democratização mais recente (Portugal, Espanha e Grécia) ter vindo a crescer, em oposição às consolidadas democracias ocidentais, que registam uma quebra do número de filiados partidários. Ao analisarem a militância partidária na Europa de 1980 a 2001 (o estudo incidiu sobre 15 países), Peter Mair e Van Biezen (2001) constatam, precisamente, uma redução do número de filiados, com a exceção da Espanha e da Grécia que registam um crescimento de $2 \%$ e 3,5\% respectivamente. Portugal regista uma quebra ligeira de 0,24\%, enquanto que as maiores perdas se verificam na Áustria e nos países nórdicos. Este processo é simultâneo a uma maior volatilidade eleitoral, ou seja, uma menor identificação partidária faz com que os eleitores sejam influenciados por acontecimentos políticos de curto prazo e pelas características dos líderes, desvalorizando as questões ideológicas.

A diminuição do número de filiados partidários é vísivel, de forma mais clara, nas consolidadas democracias do norte e centro europeu, uma vez que nos países do sul da Europa ainda se assiste a um crescimento do número de filiados, embora ténue. Convém igualmente referir que esta não é uma tendência generalizável e aplicável a todo o espectro político-partidário, uma vez que se verifica um reforço dos partidos que Oreste Massari (2004) classifica como de "esquerda libertária" e de "extrema-direita pós-industrial", nomeadamente em virtude de centrarem a sua ação em temas específicos e que vão ao encontro das necessidades e expectativas de uma considerável parte do eleitorado.

Paul Whiteley (2009, pp. 2-4) refere as dificuldades para compreender, de forma rigorosa, o declínio do número de filiados partidários em alguns Estados europeus, avançando com duas hipóteses para explicar este fenómeno, a saber: a relação entre os partidos e o Estado acaba por minar o voluntarismo partidário, no sentido em que os filiados se transformam, progressivamente, em "funcionários do Estado não remunerados" e o seu contributo financeiro (quotas e donativos) é substituído pelas subvenções estatais. A segunda hipótese remete para o crescimento de novas formas de participação, nomeadamente ao nível dos movimentos de cidadãos e das potencialidades das novas tecnologias, numa época em que as "velhas clivagens" dão lugar a valores pós-materialistas. A este respeito Massari (2004) destaca a evolução dos "partidos verdes" e dos "partidos de extrema-direita", realçando o significativo crescimento eleitoral destes partidos. No caso português este fenómeno não é percetível, no primeiro caso pelo facto do Partido 
Ecologista "Os Verdes" se apresentar coligado em eleições com o Partido Comunista Português, formando a Coligação Democrática Unitária e no segundo caso em virtude da reduzida expressão eleitoral do Partido Nacional Renovador (nas eleições legislativas de 2015 obteve $0,5 \%$ dos votos registados). No caso português, e no que diz respeito à luta eleitoral, verifica-se a possibilidade de candidaturas de movimentos independentes às eleições autárquicas (assembleia de freguesia, assembleia municipal e câmara municipal), sendo que se considera que existe uma compatibilidade entre os grupos de cidadãos eleitores e os partidos, numa perspetiva que reconhece que "aqueles grupos não se organizam nem se afirmam contra os partidos mas se complementam, contribuindo assim para o reforço quer da democracia representativa quer da democracia participativa" (Meirinho Martins, 2003, p. 37).

Tal como os resultados do projeto MAPP (Members and Activists of Political Parties) têm demonstrado, no plano internacional, também na maioria dos partidos Portugueses com assento parlamentar, verifica-se uma tendência genérica para o declínio da atividade partidária (Lisi \& Espírito Santo, 2017, p. 271). Em termos longitudinais, entre 1974 e 2014 , esse decréscimo, cifrou-se na ordem dos $30 \%$, com valores de cerca de $2 \%$ por ano (Almeida Correia, 2017). Esse declínio pode ser visto como um sinal importante sobre a perda de importância dos partidos como vetores tradicionais e fundamentais para o desenvolvimento e a confiança da democracia.

\section{INQUÉRITO À FILIAÇÃo PARTIDÁRIA: DADOS EMPÍRICOS PRINCIPAIS}

\section{NotA METODOLÓGICA}

A nível metodológico, o questionário foi alojado numa plataforma online, enviado a todos os membros dos três partidos em estudo. Na elaboração do questionário foram seguidas as seguintes linhas de orientação, de modo a permitir os objetivos traçados no início da investigação: o questionário foi dividido em três partes (características sócio-demográficas; ativismo político/partidário e ideologia; e opinião política) de modo a traçar um quadro concreto sobre o posicionamento dos filiados face à estrutura social portuguesa e ao enquadramento ideológico do partido.

A análise dos resultados teve em consideração o número total de respostas obtidas e validadas. No plano das limitações à investigação consideramos que apesar da quase totalidade dos filiados inscritos nos partidos ter fornecido conta de email ao partido, e ser a newsletter o modo corrente de contato com os filiados do partido, a mobilização para a resposta pode ser infuenciada por aspetos como a prática de acesso e resposta por email e a motivação e envolvimento na estrutura partidária. Outra limitação centra-se na comparação entre dados de filiados partidários (caso do PS e CDS/PP) e delegados partidários (PSD). Na nossa perspetiva tomamos a amostra de delegados do PSD como tendo características idênticas às dos restantes filiados, uma vez que o processo de seleção pauta-se por alguma diversidade em termos de vários aspetos como a representatividade geográfica, demográfica e envolvimento nas atividades partidárias. Não obstante estes aspetos, há que ter em conta alguma reserva em termos de análise e 
extrapolação dos resultados obtidos. Os nossos esforços no sentido da mobilização dos partidos para este tipo de investigação foram inúmeros e nem sempre fáceis. De notar a grande disponibilidade e abertura do CDS/PP para este tipo de investigação académica.

\begin{tabular}{|c|c|c|c|c|c|c|}
\hline PARTIDO & $\begin{array}{c}\text { \% votos } \\
\text { (ELEIÇÕES } \\
\text { 2011) }\end{array}$ & $\begin{array}{c}\text { \% VOTOS } \\
\text { (ELEIÇÕES } \\
\text { 2015) }\end{array}$ & $\begin{array}{c}\text { TIPO DE } \\
\text { FILIADOS }\end{array}$ & $\begin{array}{c}\text { (N RESPOS- } \\
\text { TAS VÁLIDAS) }\end{array}$ & $\begin{array}{c}\text { (N } \\
\text { UNIVERSO) }\end{array}$ & $\begin{array}{l}\text { DATA DA } \\
\text { RECOLHA } \\
\text { DE DADOS }\end{array}$ \\
\hline PS & 28,1 & 32,1 & Filiados & 1.347 & 83.524 & $2014^{*}$ \\
\hline PSD & 38,5 & $36,6 * \cdots *$ & Delegados & 313 & 1.000 & $2014 * *$ \\
\hline CDS-PP & 11,7 & & Filiados & 1.444 & 29.655 & 2013 叔火 \\
\hline
\end{tabular}

Tabela 3: Dados do contexto eleitoral e amostras dos filiados nos inquéritos aos partidos portugueses

$$
\begin{aligned}
& \text { Notas: } \\
& \text { * 01/2014 a } 02 / 2014 \\
& \text { ** } 01 / 2014 \text { a } 02 / 2014 \\
& \text { XXV Congresso do PSD, Lisboa, 21-23 de fevereiro de } 2014
\end{aligned}
$$

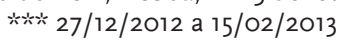

$$
\begin{aligned}
& \text { ***** PSD e CDS/PP juntos em coligação (PàF, "Portugal à Frente") }
\end{aligned}
$$

\section{CARACTERÍSTICAS SÓCIO-DEMOGRÁFICAS DOS FILIADOS}

Um dos aspetos centrais do exercício da actividade política prende-se com a procura da igualdade de género, por enquanto ainda no plano formal. Não é nosso propósito discorrer sobre as causas e as motivações para uma maior participação dos homens na política e nos partidos, nem sobre as vias existentes para atenuar esse fosso, tal como a aplicação da Lei da Paridade ${ }^{3}$ mas enunciaremos as diferenças que se verificam entre sexos no plano da filiação partidária. No estudo realizado constata-se, através da Tabela 3, um domínio muito evidente dos homens ao nível da filiação partidária. Subscrevemos, por isso, as palavras de Margarida Fernandes e Maria Estrela Duarte (1985, p. 7) quando afirmam que

o desfasamento entre o estatuto legal das mulheres e a sua ausência dos órgãos de decisão é revelador de uma discriminação, entendendo-se por discriminação o afastamento de um grupo social, neste caso as mulheres, dos órgãos e instituições, nomeadamente, a seleção no acesso a postos de decisão em função do sexo.

Portugal foi o último país da União Europeia a reconhecer o direito de voto, sem quaisquer restrições, às mulheres (após a revolução de 25 de abril de 1974). A disparidade em termos da diferença temporal da conceção deste direito nos países da União Europeia é significativa, uma vez que alguns países reconheceram a igualdade de acesso ao voto no início do século XX, cerca de 60 anos antes do nosso país. Este fator poderá ser revelante para explicar a reduzida participação das mulheres na atividade política,

\footnotetext{
${ }^{3}$ Referimo-nos à Lei Orgânica n. ${ }^{\circ} 3 / 2006$ de 21 de agosto que estabelece que tanto os homens como as mulheres deverão representar no mínimo $33 \%$ da composição das listas às eleições legislativas nacionais, às eleições autárquicas e às eleições para o Parlamento Europeu.
} 
nomeadamente ao nível do exercício de cargos no Governo e da função de deputado na Assembleia da República.

\begin{tabular}{|c|c|c|c|c|}
\hline & PARTIDo & PS & PSD & CDS \\
\hline \multirow{3}{*}{ Sexo } & Masculino & 75,4 & 82,7 & 74,0 \\
\hline & Feminino & 24,6 & 17,3 & 26,0 \\
\hline & Total $(\mathrm{N})$ & $(1.347)$ & (313) & $(1.449)$ \\
\hline \multirow{5}{*}{ Idade } & $<35$ & 16,9 & 25,6 & 26,1 \\
\hline & $36-64$ & 66,2 & 67,0 & 68,3 \\
\hline & $65>$ & 16,9 & 7,4 & 5,6 \\
\hline & Média & 49,7 & 44,5 & 43 \\
\hline & Total $(\mathrm{N})$ & $(1.346)$ & $(312)$ & $(1.735)$ \\
\hline \multirow{4}{*}{ Formação } & Nenhuma/Ensino básico & 9,4 & 0,3 & 6,5 \\
\hline & Ensino secundário & 26,0 & 19,6 & 25,0 \\
\hline & Ensino superior & 64,6 & 80,1 & 69,5 \\
\hline & Total $(\mathrm{N})$ & $(1.347)$ & $(312)$ & $(1.735)$ \\
\hline \multirow{7}{*}{ Ocupação } & Ativo & 64,3 & 81,2 & 76,1 \\
\hline & (Pré) reformado & 21,3 & 8,0 & 7,3 \\
\hline & Estudante & 3,2 & 2,9 & 6,5 \\
\hline & Desempregado & 7,4 & 3,2 & 9,3 \\
\hline & Outro & 3,8 & 5,7 & 0,8 \\
\hline & Total $(\mathrm{N})$ & $(1.243)$ & (313) & $(1.421)$ \\
\hline & Setor publico & 41,9 & 43,3 & 31,7 \\
\hline \multirow[t]{5}{*}{ Setor professional } & Setor privado & 30,7 & 33,4 & 64,9 \\
\hline & Setor do voluntariado & 27,4 & 23,3 & 3,3 \\
\hline & Total $(\mathrm{N})$ & $(1.243)$ & (305) & $(1.246)$ \\
\hline & Todas as semanas, ou mais & 8,1 & 17,6 & 23,7 \\
\hline & Poucas vezes por mês & 8,2 & 27,3 & 14,8 \\
\hline \multirow[t]{3}{*}{ Prática religiosa } & Poucas vezes por ano & 35,0 & 46,0 & 36,8 \\
\hline & Quase nunca, ou nuca & 48,8 & 19,2 & 24,6 \\
\hline & Total $(\mathrm{N})$ & $(1.347)$ & $(313)$ & $(1.396)$ \\
\hline \multirow{5}{*}{ Religiosidade } & Não religioso de todo & 24,4 & 7,3 & n.d. \\
\hline & Não religioso & 30,7 & 17,9 & n.d. \\
\hline & Algo religioso & 40,9 & 65,8 & n.d. \\
\hline & Muito religioso & 4,0 & 8,3 & n.d. \\
\hline & Total (N) & $(1.347)$ & (311) & \\
\hline \multirow{2}{*}{ Membro de sindicato } & Membro & 25,6 & 22,0 & 13,0 \\
\hline & Total $(\mathrm{N})$ & $(1.337)$ & $(313)$ & $(1.735)$ \\
\hline
\end{tabular}

Tabelao 4: Perfil sociodemográfico dos membros partidários (\%) - Portugal

Fonte: Espírito Santo e Lisi (2014); Lisi, Espírito Santo e Costa (2017)

No plano etário dos membros partidários, os três partidos apresentam uma representação bastante proporcional das diversas faixas etárias ${ }^{4}$, o que permite constatar alguma capacidade de revitalização como também evidenciar grupos de filiados intergeracionais. No plano da resposta via eletrónica os grupos a partir dos 65 anos aparecem

\footnotetext{
${ }^{4}$ As faixas etárias utilizadas na amostra seguem as do questionário aplicado através do MAPP.
} 
menos representados na amostra, o que é natural, tendo em conta a menor inclusão deste grupo a nível da tecnologia via internet.

Um dos aspetos intrigantes de análise prende-se com a questão da religião e a afirmação de crenças religiosas no seio dos filiados partidários. Apesar da reduzida identificação com a fé católica, em geral por parte de todos os filiados em estudo, o grau de participação em atividades religiosas assume alguma diferenciação entre os filiados do CDS/PP, os quais tendem a ter uma prática religiosa mais frequente. Neste caso concreto partimos de uma base ideológica partidária com raízes cristãs, visíveis na própria fundação do partido, baseado nos princípios da democracia cristã.

A Tabela 4 permite verificar que a grande maioria dos filiados possui uma qualificação de nível superior, nomeadamente licenciatura, mestrado ou doutoramento. Não são notórias diferenças entre os três partidos, apesar de uma ligeira acentuação de valores no caso dos membros do PSD, considerando um mais elevado grau de habilitações. Aquela tendência poderá ser explicada pelas alterações profundas na sociedade portuguesa, a nível educacional, e pela proliferação de cursos superiores, criados, sobretudo, após a instauração do regime democrático em Portugal. Contudo, quando comparados com os dados recolhidos para este universo de filiados partidários nos anos 80 (Stock \& Rosa, 1985, pp. 70-72) verifica-se uma evolução mais positiva e divergente.

Da análise laboral verifica-se que o partido com maior número de membros no setor privado é o CDS/PP, com cerca de $65 \%$ dos filiados a trabalhar no setor privado, contra cerca de $32 \%$ que afirmam trabalhar no setor público. No PS e no PSD a proporção de filiados que são funcionários públicos ronda valores acima dos $40 \% 5$. Esta perspetiva é contrabalançada no que diz respeito à proporção de pertença no que diz respeito ao sindicalismo. Uma minoria de filiados refere pertencer a algum sindicato. Tal como evidenciado em estudo anterior (Lisi, Espírito Santo \& Costa, 2017, p. 117), do total de respostas positivas destaca-se a pertença a sindicatos associados ao ensino (professores), bem como sindicados associados ao setor da banca (trabalhadores da banca). $\mathrm{Na}$ realidade empresarial portuguesa, as duas maiores centrais sindicais, CGTP - Confederação Geral dos Trabalhadores Portugueses e UGT - União Geral de Trabalhadores são frequentemente conotadas com a linha política do PCP e do PS respetivamente, embora não exista qualquer relação formal entre as duas entidades.

\section{RAZÕES PARA SER-SE FILIADO PARTIDÁRIO E ATIVISMO PARTIDÁRIO}

Ao analisarmos o fenómeno da militância partidária, importa verificar um conjunto de variáveis que poderão influenciar esse processo. Procurou-se perceber as reais motivações de adesão ao partido. Nesta questão o enfoque é dado às motivações individuais para a filiação. Numa breve análise verifica-se que os inquiridos destacam a importância de defender os ideais do partido, bem como a vontade de ser politicamente ativo, logo seguido pelo desejo de tomar parte ativa na escolha dos candidatos a eleições. Por outro lado, destaque-se o pouco relevo dado às últimas opções, nomeadamente,

\footnotetext{
${ }^{5}$ Refira-se que esta foi a questão que obteve um menor número de respostas. No total foram validadas menos respostas,
} o que poderá corresponder a algum receio dos inquiridos em manifestarem a sua área de trabalho. 
os hipotéticos benefícios da militância, o contexto familiar e o contributo financeiro ao partido. Não se verificam, nesta questão diferenças significativas entre membros de diferentes partidos, o que demonstra que a vontade da filiação partidária tende a conter um conjunto básico de motivações comuns independentemente do partido.

\begin{tabular}{|c|c|c|c|}
\hline TORNEI-ME MEMBRO DO PARTIDO PORQUE ... & PS & PSD & CDS \\
\hline Queria conhecer pessoas politicamente activas & $3.1(1.2)$ & $3.0(1.2)$ & $3.4(1.2)$ \\
\hline Queria ser politicamente ativo & $3.9(1.1)$ & $3.9(1.1)$ & $3.7(1.2)$ \\
\hline Queria ajudar a concretizar os ideais do partido que eu apoiava & $4.4(0.8)$ & $4.4(0.8)$ & $4.5(0.8)$ \\
\hline Queria influenciar a escolha dos candidatos a eleições & $3.2(1.2)$ & $2.9(1.2)$ & $3.5(1.2)$ \\
\hline Pretendia fazer carreira política & $2.1(1.1)$ & $2.2(1.1)$ & $2.3(1.2)$ \\
\hline Pretendia ajudar financeiramente o partido & $2.0(1.0)$ & $1.7(0.9)$ & $2.1(1.0)$ \\
\hline $\begin{array}{l}\text { Pretendia obter benefícios profissionais do exercício da actividade } \\
\text { política }\end{array}$ & $1.5(0.8)$ & $1.4(0.7)$ & $1.7(1.0)$ \\
\hline Tive influência do contexto familiar & $2.0(1.2)$ & $2.1(1.2)$ & $2.2(1.2)$ \\
\hline
\end{tabular}

Tabela 5: Razões para se tornar membro partidário (média) - Portugal

Fonte: Espírito Santo e Lisi (2014); Lisi e Cancela (2017)

Nota: os números são a média e em parêntesis o desvio padrão. Cada questão é baseada num item ou proposição (resposta múltipla). Para cada item, os inquiridos tiveram a oportunidade de dizer se o motivo era completamente irrelevante (1), não muito relevante (2), relevante (3), bastante relevante (4) ou muito relevante (5). Não sei e não responde foram excluídos da análise

Diferentes níveis de ativismo partidário têm sido considerados desde o estudo seminal de Duverger (1951), o qual identificou diferentes graus de participação na atividade de membros: simpatizantes, adeptos, militantes e propagandistas. Os níveis de proximidade ao partido têm vindo a ser discutidos por diversas outras contribuições posteriores (Katz \& Mair 1995; Krouwel 2012; van Haute \& Gauja, 2015), que têm procurado examinar a proximidade dos membros partidários à organização partidária, em várias democracias. O ativismo partidário aponta para uma questão do grau de compromisso, para os direitos que se adquirem na estrutura do partido e para a intervenção dos membros partidários no seu partido.

Este indicador permite-nos aferir da envolvência do filiado para com o partido e a sociedade que o rodeia. Cada filiado é um potencial angariador de novos membros, dependendo esse aspeto do grau de integração do filiado, bem como dos seus próprios objetivos no seio da organização. No que diz respeito ao grau de participação dos filiados na vida partidária foi desenvolvida uma série de questões de forma a aferir se os militantes têm uma participação ativa, dando sequência à separação concetual entre a perspetiva de "filiado" e de "militante".

Pela análise da Tabela 6, abaixo, verifica-se que uma parcela dos filiados não desenvolve qualquer trabalho para o partido numa base mensal. Este indicador permite verificar a envolvência dos filiados no seio da atividade do partido, sendo que o menor grau de participação pode resultar de grande parte das atividades diárias ser realizada por um conjunto de profissionais da política, funcionários do próprio partido. 


\begin{tabular}{|c|c|c|c|c|}
\hline PARTIDo & & PS & PSD & CDS \\
\hline \multirow{4}{*}{$\begin{array}{l}\text { Tempo dedicado às ativida- } \\
\text { des partidárias por mês }\end{array}$} & 0-5 horas & 79,4 & 62,2 & 69,0 \\
\hline & 6-10 horas & 13,3 & 23,1 & 11,9 \\
\hline & Mais de 10 & 7,3 & 14,7 & 19,1 \\
\hline & Total $(\mathrm{N})$ & $(1.220)$ & 422 & $(1.069)$ \\
\hline \multirow{6}{*}{$\begin{array}{l}\text { Participação nos eventos partidá- } \\
\text { rios nos últimos } 12 \text { meses }\end{array}$} & $\begin{array}{l}\text { Uma vez por se- } \\
\text { mana ou mais }\end{array}$ & 16,8 & 35,5 & n.a. \\
\hline & Duas vezes por semana & 19,2 & 33,3 & n.a. \\
\hline & Uma vez por mês & 17,0 & 12,1 & n.a. \\
\hline & Mais de 6 vezes por ano & 17,2 & 9,9 & n.a. \\
\hline & $0-6$ vezes por ano & 24,1 & 9,2 & n.a. \\
\hline & Total $(\mathrm{N})$ & $(1.092)$ & 452 & \\
\hline \multirow{5}{*}{ Perceção do envolvimento partidário } & Muito ativo & 19,4 & 41,2 & 11,8 \\
\hline & Bastante ativo & 50,4 & 56,9 & 38,1 \\
\hline & Não muito ativo & 24,0 & 1,6 & 32,9 \\
\hline & Nada ativo & 6,2 & 0,3 & 17,2 \\
\hline & Total $(\mathrm{N})$ & $(1.346)$ & $(313)$ & $(1.189)$ \\
\hline
\end{tabular}

Tabela 6: Nível e tipo de ativismo (\%) - Portugal

Fonte: Espírito Santo e Lisi (2014); Lisi e Cancela (2017)

Foram feitas algumas perguntas sobre a participação dos filiados na vida do partido, a fim de avaliar se estes desempenham um papel ativo, de acordo com a diferença conceitual entre "membro" e "ativista".

O indicador composto pelo número de horas dedicadas a atividades partidárias numa perspetiva semanal e mensal permite constatar o grau de afinidade do filiado com o seu partido, embora não permita aferir a qualidade da participação e o seu fiel compromisso com os valores e as ideologias do partido. Outro aspeto relevante prende-se com o background familiar e com o ambiente laboral em que os cidadãos estão inseridos. Kriegel (1986) refere precisamente que parte da atividade dos filiados do partido comunista francês passa pelo local de trabalho, numa aparente interligação com o movimento sindical. Lagroye, Lorde e Mounier-Chazel (1976) num inquérito realizado em 1975 desmistificam a ideia de que o militantismo era um fenómeno dos partidos de esquerda, embora confirmem que é no seio destes partidos que se verifica uma participação política mais ativa. Numa outra contribuição, em que se analisa o militantismo partidário belga, Emily van Haute (2011) constata a pouca apetência dos filiados para dispender tempo no exercício de tarefas para o partido, sendo que traça, de forma genérica, um quadro do militante partidário: homem, de meia-idade, com elevado nível de instrução e profissionalmente ativo.

Numa perspetiva longitudinal, Whiteley e Seyd (2002) e Witheley (2009) têm analisado o fenómeno do militantismo no Reino Unido, dando enfâse à questão da classe social e da educação como variáveis explicativas de uma maior participação política. 
Recorrendo aos dados recolhidos da "ISSP Citizenship Survey" em 36 países, num total de 50 mil inquéritos recolhidos, constata-se a existência de dois modelos centrais de explicação da envolvência dos cidadãos nos partidos políticos, a saber: o modelo cívico voluntário, que defende a ideia que a participação política resulta dos recursos de cada indivíduo (Verba \& Nie, 1972; Whiteley, 2009) e os modelos de relação cognitiva, que justificam a participação com a "habilidade e vontade de processar e compreender informação sobre política e sociedade" (Whiteley, 2009, p. 11).

As constantes mudanças na estrutura e no funcionamento dos partidos têm reflexos na sua capacidade de angariação, sendo que de um modo arrojado podemos atestar que a equação de "partidos sem filiados" é atualmente viável (van Haute, 2011). Neste ponto pode ser defensável a inexistência de uma participação ativa e decisiva por parte dos filiados para a afirmação do partido. Para Portugal, não se trataria de advogar a possibilidade de um partido sem filiados em termos efetivos, uma vez que a legislação prevê a obrigatoriedade da sua existência. No entanto, a competição partidária nacional poderá não perder capacidade política e social efetiva pela diminuição do efetivo partidário, uma vez que a projeção pública dos partidos depende manifestamente mais da sua capacidade de mobilização política e eleitoral através dos média do que do número do efetivo no terreno. Constatam-se ainda capacidades de recrutamento bastante diferentes entre partidos, sendo que Delwitt (2000) refere que este fenómeno é, essencialmente, visível nos partidos de massas, onde o aumento de filiados é verificável em partidos que assumem temas fraturantes ou específicos no seio da sociedade. Como exemplo referimos os partidos de extrema-direita ou os partidos ecologistas. No contexto português não é percetível o crescimento da extrema-direita. No entanto, próximo da extrema-esquerda salienta-se o posicionamento alcançado pelo Bloco de Esquerda, um partido baseado na adoção de temas fraturantes (como a interrupção voluntária da gravidez ou o casamento entre pessoas do mesmo sexo).

Encontramos nestes dados uma tendência que poderá ser explorada e desenvolvida pelas máquinas partidárias. Em geral, é elevado o número de filiados sem qualquer participação neste tipo de eventos, pelo que existe margem para compreender a falta de motivação para a presença e o contributo neste tipo de participação. Pontualmente diferenças entre partidos podem ser decorrentes da posição de "delegado" face a "membro partidário", como será o caso desta questão (Tabela 6). O mesmo pode ser afirmado em relação à questão seguinte, sobre o grau de participação nas atividades do partido. $A$ tendência é para uma auto-definição como "razoavelmente ativo", ou seja, uma posição intermédia num plano de compromisso com a atividade partidária.

\section{NOTA FINAL}

Novos movimentos sociais afirmam-se como um desafio à democracia e ao quadro político instalado, criando alternativas à participação e ao envolvimento cívico dos cidadãos na sociedade. Não equacionamos a existência de partidos sem filiados, mas o atual cenário implica uma redefinição clara do seu papel e da sua importância na 
concretização dos objetivos do partido. Este novo espectro político e social tem sido equacionado pelos partidos de massas, numa tentativa de alcançar uma maior franja do eleitorado.

O papel desempenhado pelos três partidos em estudo, PS, PSD e CDS/PP como partidos de governo, e o seu enquadramento político no panorama nacional conduziu-nos a um levantamento sobre a sua estrutura filiativa, as características sóciodemográficas dos seus membros e o respetivo processo de filiação partidária, tanto ao nível das motivações, bem como o grau e tipo de participação desenvolvido.

Os filiados partidários são maioritamente homens, num universo, em termos etários, heterogéneo, qualificado, e maioritariamente empregado. Os filiados assumem-se em termos de estratificação social como pertencendo à classe média, pouco religiosos, resultado um processo de filiação diluído ao longo do tempo, o qual nos permite afirmar que, em grande medida, existe uma base de mobilização partidária, nos partidos em estudo, e com sentido de rejuvenescimento. A caminhada de um filiado até tornar-se militante pode não chegar a ser efetiva, sendo que este estudo demonstra a distância entre um nível e outro, como sendo de interesse aprofundar, particularmente, pela baixa proporção de militantes "ativos", e com disponibilidade política para se entregarem à militância partidária.

Importa, igualmente, lançar um olhar sobre o fenómeno dos ex-filiados, ou seja, cidadãos que em determinado momento da sua vida decidiram abandonar a militância partidária, sendo naturalmente difícil equacionar as motivações na base destas decisões, nomeadamente devido às dificuldades de acesso a esses dados. A emergência de novas formas de participação política poderá constituir um novo atrativo para os filiados partidários, que encontram nas estruturas partidárias diversos entraves à sua ascensão.

\section{REFERÊNCIAS BIBLIOGRÁFICAS}

Almeida Correia, S. (2017). A Evolução da Militância em Portugal: Enquadramento Legal e Tendências Longitudinais. In M. Lisi \& P. Espírito Santo (Eds.), Militantes e ativismo nos partidos políticos - Portugal em perspetiva comparada (pp. 29-68). Lisboa: ICS.

Almond, G.; Powell, B.; Strom, I. \& Dalton, R. (2000). Comparative Politics Today - A World View. EUA: Longman.

Berger, P. \& Luckman, T. (1961). A Construção Social da Realidade. Petrópolis: Vozes.

Berelson, B. \& Grazia, S. (1947). Detecting Collaboration in Propaganda. Public Opinion Quarterly, 11, $244-253$.

Braga da Cruz, M. B. (1985). A participação política da juventude em Portugal. Análise Social, 21, 1067-1088.

Cabral, M. V. (1995). Grupos de Simpatia Partidária em Portugal: perfil sóciográfico e atitudes sociais. Análise Social, $30,175-205$.

Delwit, P. (2000). Participation electorale et crutin europeen: une legitimite minimale. In G. Grungberg; P. Perrineau \& C. Ysmal (Eds.), Le Vote des Quinze: Les Élections Européennes du 13 Juin 1999, (pp. 295-316). Paris: Press de Science Po. 
Dogan, M. (1995). Erosion of Class Voting and of the Religious Vote in Western Europe. International Social Science Journal, XLVII, 525-538.

Duverger, M. (1951). Les Partis Politiques. Paris: Librairie Armand Colin.

Espírito Santo, P. (2011). Sociologia Política e Eleitoral. Modelos e explicações de voto. Lisboa: ISCSP. Second edition.

Espírito Santo, P. do \& M. Lisi. (2014). Filiados e Delegados dos Partidos: Portugal em Perspetiva Comparada. Base de dados. Lisboa: ISCSP-UL e FCSH-UN. Projeto MAPP. Retirado de: http://www.projectmapp.eu/

Fernandes, M. \& Duarte, M.E. (1985). A mulher e a política. Lisboa: Comissão da Condição Feminina.

Figueiras, R. \& Fonseca, J. (2017). Padrões de comunicação interna nos partidos políticos portugueses: o caso do PSD, PS e CDS/PP. In M. Lisi \& P. Espírito Santo (Eds.), Militantes e ativismo nos partidos políticos - Portugal em perspetiva comparada (pp. 213-246). Lisboa: ICS.

Gray, M. \& Caul, M. (2000). Declining voter turnout in advanced industrial democracies, 1950 to 1997: the effects of declining group mobilization. Comparative Political Studies, 33(9), 1091-1122.

Harrop, M. \& Miller, W. (1987). Elections and Voters - A comparative introduction. G.B.: Macmillan.

Katz, R. S. \& Mair, P. (1992). The Membership of Political Parties in European Democracies, 1960-1990. European Journal of Political Research, 22, 329-45.

Katz, R. S., \& P. Mair. (1995). Changing Models of Party Organization and Party Democracy: The Emergence of the Cartel Party. Party Politics, 1, 5-28.

Katz, R.S. \& Mair, P. (2009). The Cartel Party Thesis - A Restatment. Perspectives on Politics, 7(4), 753-766.

Kirchhmeimer, O. (1966). The Transformation of Western European Party Systems. In J. LaPalombara \& M. Weiner (eds.), Political Parties and Political Development (pp. 177-200). New Jersey: Princeton University Press.

Kriegel, B. (1986). Les Chemins de l'État. Paris: Calmann-Lévy.

Krouwel, A. (2012). Party Transformations in European Democracies. Nova lorque: SUNY press.

Lagroye, J.; Lord, G. \& Mounier-Chazel, L. (1976). Les militants politiques dans trois parties français. Paris: Pedone.

Lasswell, H. (1931). The measurement of public opinion. The American Political Science Review, 25, 311-326.

Lisi, M. \& Espírito Santo, P. (Eds.) (2017). Militantes e ativismo nos partidos políticos - Portugal em perspetiva comparada. Lisboa: ICS.

Lisi, M.; Espírito Santo, P. \& Costa, B. (2017). Filiados e ativismo partidário em Portugal: enquadramento teórico e características do inquérito. In M. Lisi \& P. Espírito Santo (Eds.), Militantes e ativismo nos partidos políticos - Portugal em perspetiva comparada (pp. 99-123). Lisboa: ICS.

Lisi, M. \& Cancela, J. (2017). Ativismo e participação nos partidos Portugueses. In M. Lisi \& P. Espírito Santo (eds.). Militantes e ativismo nos partidos políticos - Portugal em perspetiva comparada (pp.125-144). Lisboa: ICS.

Mair, P. (2003). Os partidos políticos e a democracia. Análise Social, 38, 277-293. 
Mair, P. \& Keman, H. (2002). Comparative Democratic Politics: A guide to contemporary theory and research. London: Sage Publications.

Mair, P. \& van Biezen, I. (2001). Party Membership in Twenty European Democracies, 1980-2000. Party Politics, 7, 5-21.

Massari, O. (2004). I Partiti Politici nelle Democrazie Contemporanee. Roma-Bari: Laterza.

Meirinho Martins, M. (2003). Participação Política e Grupos de Cidadãos Eleitores. Lisboa: ISCSP.

Norris, P. (1997). Electoral Change since 1945. USA: Blackwell Publishers.

Norris, P. (2002). Digital Divide: Civic Engagement, Information Poverty and Internet Worldwide. Cambridge: Cambridge

Oppo, A. (1986). Socialização Política. In N. Bobbio; N. Matteucci \& G. Pasquino (Eds.), Dicionário de Política. Brasília: UNB.

Pennings, P. \& Hazan, R.Y. (Eds.) (2001). Democratizing Candidate Selection: Causes and Consequences. Party Politics, 7(3), 267-380.

Popper, K. \& Condry, J. (1993). La television: un danger pour la démocratie. France. Paris: Anatolia Editions.

Poguntke, T.; Scarrow, S. E. \& Webb, P. (2016). Party Rules, Party Resources and the Politics of Parliamentary Democracies: How Parties Organize in the 21st Century. Party Politics, 22(6), 661-678.

Scarrow, S. (2002). Perspectives on Political Parties: Classic Readings. USA: Palgrave Macmillan US.

Scarrow, S., Webb, P. \& Farrell, D. (2000). From Social Integration to Electoral Contestation: The Changing Distribution of Power Within Political Parties. In R. Dalton \& M. Wattenberg (Eds.), Parties Without Partisans: Political Change in Advanced Industrial Democracies. Oxford: Oxford University Press.

Stock, M. J.; Silva, A.; Valente Rosa, L. F.; Martins d'Oliveira, C. A.; van Schuur, T. \& Antunes, L. F. C. (1985). Os Partidos em Congresso 1981 - Quem São e o que Pensam os seus Delegados - uma Abordagem Sociológica. Economia e Sociologia, $38 / 39$ (separata, pp. 1-208).

Stock, M. J. \& Valente Rosa, L. F. (1985). Perfil dos Delegados aos Congressos dos Partidos Políticos em 1981. Economia e Sociologia, 38/39, 59-94.

van Haute, E. (2011). Party Membership in Europe: Exploration into the anthills of party politics. Bruxelles: Editions de l'Université de Bruxelles.

Verba, S. \& Nie, N.H. (1972). Participation in America. New York: Harper and Row.

Wattenberg, M.P. \& Dalton, J. (2000). Parties without partisans. Oxford: Oxford University Press.

Witheley, P. (2009). Is the Party Over? - The Decline of Party Activism and Membership across the Democratic World. Essex: University of Essex.

\section{OUTRAS REFERÊNCIAS}

Comissão Nacional de Eleições: www.cne.pt

Members and Activists of Political Parties (MAPP): http://www.projectmapp.eu/ 


\section{NOTAS BIOGRÁFICAS}

Paula do Espírito Santo é investigadora do CAPP - Centro de Administração e Políticas Públicas e Professora do Instituto Superior de Ciências Sociais e Políticas da Universidade de Lisboa.

E-mail: gaborone2008@gmail.com

Endereço: Rua Francisco Roque Aguiar, $n^{\circ}$ 1, ed. 2, R/C Esq. 2780-056 Oeiras

Bruno Ferreira da Costa é professor auxiliar convidado na Universidade da Beira Interior, Departamento de Comunicação e Artes.

E-mail: bdfc@ubi.pt

Endereço: Departamento de Comunicação e Artes, Universidade da Beira Interior. Convento de Sto. António, 6201-001, Covilhã, Portugal

* Submetido: 28/05/2017

* Aceite: 18/07/2017 